\title{
Education and Recognition:
}

\section{Is Democracy What We Are Really Looking for?}

\author{
Francesco Forlin \\ University of Perugia
}

\begin{abstract}
Democracy provides a quite peculiar kind of recognition, based on the following theory: Since contents tend do make human beings struggle and since strong decisions tend to make this struggle even harder, forms have to be more important than contents and decisions have to soft. Thus, I believe, we tend to mix up complexity and uncertainty. It is therefore possible to criticize this theory by assuming that it is needed to find a way to embrace true complexity, namely complexity related to the relational nature of human beings. In order to achieve such objective, I will briefly trace the research back to G. W. F. Hegel's method, to W. von Humboldt's educational thought and to R. Tuomela's insights on intersubjectivity.
\end{abstract}

Keywords: education, recognition, intersubjectivity, decision, complexity, democracy, tradition, identity, collective agency

In this talk, I will try to briefly underline the relation which ties recognition and education by means of a possible critic to some directions contemporary democracy has taken.

I'm starting with a quote from Hegel where he defines Analytische Methode a method which goes straight to the Different (das Unterschiedene) as something which is in front of the sentient being. According to Hegel, recognition means here to dissolve what is given (das gegebene Konkrete aufzulösen) grasping from it its very essence, which mainly consists in power and law.

It is highly interesting to stress this point: The further we go in this direction, the more we will find ourselves quite far from what we nowadays call democracy. In western countries, democracy is normally associated with a system whose citizens are capable of monitoring the government and where power is supposed to follow a bottom-up direction rather than a top-down one.

In this case, recognition concerns more the individuals than the institutions, which are most likely supposed to play the role of what we could define as a referee, making sure that the commonly decided rules are well respected by all the players involved in the match. However, it is possible to argue that our current declination of democracy could simply be wrong.

Blocked by our many ties and boundaries - which are eventually there to ensure that nobody, and mostly governments, can take a decision overruling the rights of the individuals-we face a peculiar moment. In my opinion, which I am pleased to share in a hopefully provocative way, it has somehow happened that, in the western world, being sensitive to complexity turned into falling in love with uncertainty. In that same moment,

Francesco Forlin, Ph.D., Department of Philosophy, Human, Social, and Education Sciences, University of Perugia, Italy; main research fields: Philosophy of Education, Theory of Intersubjectivity, German Idealism, and History of Philosophy. 
we passed from policy of correctness to politically correct, which means making form more important than content. In such a society, recognition means nothing more than formal inclusion, regardless of the contents which are shared since they tend to divide persons according to their cultural and religious heritage.

I believe that here we find a big misunderstanding regarding what this heritage is. According to the systems theory thinker Niklas Luhmann, modern society begins by refusing to be an organization, which means that modern societies are lacking a center as well a hierarchy: Individuals are meant to remain separate from each other. Modern societies do not include the idea of a fully-developed inclusion of individuals, and, which is more interesting, this is Luhmann's idea of complexity. Going back to my former Hegel quote, it is as if Luhmann was saying that das gegebene Konkrete which is aufzulösen in order to grasp the essence is precisely the heritage that makes individuals part of something greater than them.

Once again: forms without contents.

A question follows: which essence are we talking about, by Hegel and by Luhmann? Clearly not the same.

If Hegel believes that what really matters (the essence) is precisely the framework which lies beyond and within every possible determination, Luhmann, on the contrary, assumes that every new distinction occurring in society leads only to a deeper complexity of the individual sphere. Nevertheless, it is possible to find a point of contact between the two authors, namely when Luhmann, referring to highly-developed societies, criticizes them by stating that given the growing complexity of deciding about decisions of decisions of decisions, we face a growing tendency towards deciding of not deciding (Luhmann-De Giorgi 2003, 331).

This is precisely what I was referring to when speaking of falling in love with uncertainty.

It seems therefore crucial to underline the importance of something which, on the contrary, many western philosophers and thinkers have tried to blame, and very often in the name of democracy: power. Foucault, for instance, stresses the link existing among power, control, and violence (a link singularly present in the German language, where the same word Gewalt refers to both power and violence). He does that in order to blame the very concept of crime, meant as the secular translation of sin used by regimes and governments to weaken and persecute those who for various reasons result as parts of the social body.

On a different level, it would be possible to state that the western system of laws, following the point of view of Corpus Iuris Civilis, refuses from the very beginning to use laws to find an intermediate point of agreement between the two contenders-just as for example happens in Chinese and others Far Eastern traditions. On the contrary, Roman right aims to separate the Good from the Evil, which obviously means that the Romans were quite sure that a Good in itself as well as an Evil in itself did really exist and stayed there to be seen and judged. By whom? By the State, of course, namely in the person of those entrusted by the laws to rule.

It is highly interesting to follow how this point of view passed directly into the Christian civilization, where what in Roman view we could call "tradition's will”-mos maiorum, the ethos of those who came before-turns into God's will. Although the change is clearly very considerable, we can observe that in both civilizations to administrate the law is equal to judge, which, if I may insist on this point, means to separate. It is interesting to highlight the German word for judgement—Ur-teil—which literally means first, original separation.

Maybe Foucault has really got a point: There is indeed a relation among power, order, and law. That's what many scholars regret, too, when they underline how problematic the cohabitation between this "Roman-Christian" point of view and contemporary democracy could be. I agree, that is why I am 
provocatively arguing that maybe in the last decades we have tried to solve this problem by letting the wrong side fall. Maybe it is not our Roman and Christian heritage the one to put aside: Maybe it is contemporary democracy both cause and effect of the impasse we are facing when it gets to recognition and education.

What both Hegel and his former contendent Von Savigny (the founder of German Historical School of Jurisprudence) can teach us regarding right, laws, recognition, and education is that, even if we try-like Hegel does - to grasp the very essence of every educational act as a product of the inner life of Geist-which is one and the same for every human being as such-everything that happens to a single man is nevertheless happening to him within the social community to which he belongs.

Hegel and Savigny had opposite ideas regarding the hierarchy between rationality and tradition, yet they both would most surely avoid one of the biggest mistakes contemporary democracy has put itself into. On the one hand, we normally refuse to consider certain rights of our culture as "facultative," but on the other hand, we keep on doing as if these aspects should not be put into relation with specific events and dynamics occurred during western history — for instance, the aforementioned encounter between Roman right and Christian thought, or between Greek philosophy and Christian theology.

There is a reason for this, and I believe it is what I previously defined as policy which prefers to underline what is politically correct more than a policy of correctness.

In other words, we face the dilemma of a western democracy which seems able to find its own identity only by denying having one. It is the idea of judgment which scares us, since it carries with it the idea of separation.

Here lies the main philosophical point. What we are trying to realize is an identity built on an apparently open form of recognition which, in truth, is blind exactly because it cannot stand reality, the toughness of separation. Not by chance contemporary philosophy seems to avoid Hegel: what western democracy really fears is not—as it is claimed — the absence of a choice, but its presence. Its real presence.

The real presence of a choice would imply the presence of a real separation, a living relation with another identity, something which does not necessarily lead to a common solution—which, on the contrary, is always possible when forms rather than contents are involved. Once again, it is when it comes to taking a decision, a real decision—a judgement-that contemporary democracy faces its daemons and its weakness. In order to avoid this critical point we have found many ways to weaken the rule of law, of governments and, philosophically said, of power in itself. Hegel seems therefore scary primarily for philosophical reasons-his absolute Geist is simply too much for a civilization which no longer trusts anything that claims to be absolute-secondarily for political reasons-nothing is more anti-contemporary than a State which is intended to take decisions that give reality to the Geist.

One of the most interesting reasons for this sounds as follows: Such an absolute and such a State could fit in the past, but would be unfit to rule the growing complexity of contemporary world.

This is a point worthy of interest, since it takes into account something which is indeed really the core of Hegel's reasoning; yet I do believe that this point of view only pretends to take complexity into account.

Complexity, according to Hegel, is only possible after a struggle. Many centuries ago, as it is known, Heraclitus saw this truth describing what Hegel calls Werden as the only and true logos. It is important to note that Heraclitus's logos is, just like Hegel's, one and the same for every rational being, which means that it is in some way highly democratic. 
But this kind of democracy can be gained only by struggling. It cannot be given. Nor can one person simply inherit it by rights of blood: Every rational being has to prove to be up to what times demand. It's not a matter of form; it's all about contents. And when it comes to contents, then separation and complexity come into play, since every single choice is a possible solution to real problems and different solutions do take different plans of actions into account, which once again means: struggle. Struggle is the key to complexity. Struggle is the structure of what does not have a preordered solution. The more free the struggle, the more coherent and valid the solution. Here lies the real challenge of both democracy and western education and way of recognition.

This challenge has to do with a rather complex dialectic between the subjective and inter-subjective dimension. No educational context can exist in the absence of collective sharing.

Besides, every educational context requires the person's training, to be effective; it requires first and foremost an "internal conversion," without which all external stimulations can only be useless. Here, then, the Harmonie which W. von Humboldt speaks of does not only refer to the attitudes of the individual man, but also to those of various individuals who interact with each other mutually. Von Humboldt was not only the founder of the University of Berlin, meant to serve as a model to all European universities, but he also gave a decisive contribution to the theoretical development of the concept of education as Bildung which has had and continues to have a big significance in Western pedagogy.

According to him, human beings must, firstly, be "educated" to harmonious development of their faculties. However human beings are, in some way, prepared for that since they are, as Raimo Tuomela writes, "a framework of agency, that assumes that normal persons are thinking, experiencing, feeling, and acting beings capable of communication, cooperation, and following rules and norms” (Tuomela 2007, 6).

Tuomela, one of the fathers of social ontology, a field of analytical philosophy particularly devoted to the study of the relation between individuals within society, reflects here on social agency and collective intentionality, and namely on what he calls I-mode and We-mode. The educational procedure requires an extremely complex sort of group thinking, and this great arrangement of human limits ought not be underestimated, since it shows up as the climax of advancement of humankind. It is focal particularly in regards to the social existence of people and their capacity to beneficially relate with collective and intersubjective organizations. The meaning of a man as a framework of agency is extremely intriguing. The individual picks up the status of a man, of being-somebody, just insofar he is ready to restricting its own individual activity. In von Humboldt's thought, the Bildung builds a Harmonie which is uncovered in the development of few resources together with the restriction of others. The Bildung, that is, comprises of an organized development of the possibility of humankind in the heart of every single individual. This is affirmed to be not just individual endeavor, but rather collective. Von Humboldt characterizes that endeavor as Verknüpfung unseres Ichs mit der Welt, the boundaries and ties that link our I and the world.

With the specific end goal to approach this issue from another perspective, I will now spend some words on Michael Bratman's position on the same topic. Bratman, the other father of social ontology, prefers to stress the importance of a fully-developed education of the individual, in order to allow the constitution of what we call an ontology-grounded society. The fundamental contrast between the hypothesis of Tuomela and that of Bratman is that while the previous spotlights on group thinking as social communication, the second spotlights on organization as connection in time, i.e., as a progression of anticipated activities that are supposed to give fruit in future. He states that the planning theory is a theory about the nature of intentions understood as central 
elements in this fundamental form of human, temporally extended agency. Such intentions bring with them a complex nexus of roles and norms that is characteristic of planning agency. And these structures go well beyond simple, temporally local desire-belief purposive agency. So it seems reasonable to see intentions, so understood, as distinctive elements of the psychic economy of planning agency. This is the distinctiveness of intention (Bratman 2014, 23-24).

Intentions, once inserted into a planning theory, reveal forms of extended agency, and as such require a capacity for action that binds them not just as individuals, as we-intentions in Tuomela, but also the present and the future. Thus, it is clear that what Bratman describes as continuity thesis:

once God created individual planning agents and placed those agents in a world in which they have relevant knowledge of each other's minds, nothing fundamentally new—conceptually, methaphysically, or normatively—needs to be added there to be modest sociality... the deep structure of at least a central form of modest sociality is constituted by elements that are continuous with those at work in the planning theory of our individual agency. (Bratman 2014, 8)

Bratman changes Tuomela's setting, which explains any minimum basis of social—modest sociality—we should build on some disruption of the individual level—the I-intentions - to embrace the collective - the We-intentions, and develops an alternative proposal which "begins by distinguishing, in the individual case, between simple goal-directed agency and planning agency. Once individual planning agency is on board, the step to modest sociality need not involve a fundamental discontinuity” (9).

It is thus planning agency what really matters in order to understand the difference between a merely individual context and an intersubjective one.

The connection between present and future is therefore inseparable from the complexity of inter-subjectivity: It is as if the output from the individual dimension and the entry in the intersubjective plan represents in ethical terms the overcoming of the dimension of single action and the acceptance of the planning of the complex.

The planning requires an understanding of agents as articulated beings, placing them within a dense network of relationships and roles, especially social, which is prerequisite for most planned actions. While, in fact, it is possible to think of simple actions conceived and carried out by an individual operating in isolation, planning requires the implementation of additional conditions that are almost never manageable by one person.

It is along these lines that Bratman presents approaches, i.e., complex activities, highlighting the character of defeasibility, which implies that they, unlike the ethical basic of Kant, don't typically recommend decisions to be taken no matter what. Differently from Tuomela, who thinks in terms of collective validation of the We-Intentions, Bratman focuses himself on the ability of the individual to perform a complex task that includes its own development over time in a community of others. Intersubjectivity is therefore required, but not as a main precondition.

What really matters here is the feasibility to plan, which means to determine the future by the means of what we want the present to become. To overcome the boundaries of reality-in order to dominate them-means therefore to master the structure of complexity. I do believe that this can only be possible thanks to a very simple core idea. To overcome what is complex requires a complex solution, yet supported by a simple core. And so I come back to my first provocative question: How did it happened that, in the western world, being sensitive to complexity turned into falling in love with uncertainty? 
Yet, what both Tuomela and Bratman underline is the link between complexity and full development of the human being: We-Intentions or planning agency require a level of complexity just like Bildung for Von Humboldt or recognition for Hegel. But—and here we discover something interesting — not only complexity, but also institutional decision is in all cases needed. All the four authors, with their different style and perspective, stress this point: neither a full recognition nor a full education can occur if not on a both complex and institutional level.

We are then forced back to face complexity, yet in order to make it compatible with social and public decisions.

There is a big difference between Hegel's philosophy—which embraces complexity and struggles with it in order to grasp the truth of its own Aufhebung and in order to fully understand the meaning of social and political institutions, which are among the most important faces of human complexity, and just because of this simply can not demand their meaning to democratic consensus - and many contemporary philosophies which seem to be satisfied with the conclusion that complexity is the final word or, even worse, than no final word exists at all.

The point is therefore: Is our democratic educational model capable of making individuals ready to stand the test of complexity?

The answer we give can have significant consequences on society.

For instance, if the contemporary theory of education keeps on forgiving what it takes to be ready for challenges and instead keeps on trying to avoid struggle, pretending it never existed, then two things will happen, and have already begun to happen:

(1) Only the few who can afford it will be in condition to receive a good education, which means a compelling and challenging education. The more we try to soften and weaken an open and clear selection, the more a selection will anyway happen, just depending on grounds which lie above the state's control, such as richness or personal connections. In this way, the highly-democratic western educational system begins to turn into its opposite.

(2) We, as a civilization, are going to be overwhelmed by countries, which—like for example Singapore, or South Corea or Hong Kong — seem to use nothing more than something very similar to our "old" educational system. This refers to a system in which education is mainly devoted to motivating and-to use the strongest word-judging student's preparation and engagement in studies. Strictly related to this praxis is the idea that when it comes to education it comes to something really important for the future of every person. It is therefore not possible to make jokes about education, since it has to do with something which needs to be taken very seriously from the very beginning of a student's life. On the contrary, many contemporary western education theories claim that we should improve the link between game and education, so that educational and learning processes can become funnier, more enjoyable, in a word: easier.

This, I believe, is the core of the problem we are facing, and the point upon which we, as teachers and researchers, are going to be judged from those who we did not prepare for what lies ahead.

\section{Works Cited}

Bratman, Michael. Shared Agency. A Planning Theory for Acting Together. New York: Oxford University Press, 2014. 
Forlin, Francesco. “Hermeneutics of the Educational Process. Bildung as Collective Intentionality.” Pedagogical Culture I (2016): 11-24.

Foucault, Michel. Surveiller et punir. Naissance de la prison (Discipline and Punish: The Birth of Prison). Paris: Gallimard, 1975. Hegel, Georg Wilhelm Friedrich. Enzyklopädie der philosophischen Wissenschaften (Encyclopedia of Philosophical Sciences). Heidelberg: Oswald, 1830.

Humboldt, Wilhelm von. Über die Verschiedenheit des menschlichen Sprachbaus und ihren Einfluss auf die geistige Entwicklung des Menschengeschlechts (On the Diversity of Human Language Construction and Its Influence on the Mental Development of the Human Species). Berlin: KAdW, 1836.

Luhmann, Niklas and De Giorgi, Raffaele. Teoria della società (Theory of Society). Milano: Franco Angeli, 2003.

Savigny, Friedrich Carl. "Über den Zweckdieser Zeitschrift (About This Journal’s Aim).” Zeitschrift für geschichtliche Rechtswissenschaft I (1815): 1-17.

Tuomela, Raimo. The Philosophy of Sociality: The Shared Point of View. New York, Oxford University Press, 2007. 